\title{
Polydopamine-Assisted Surface Modification of Ti-6Al-4V Alloy with Anti-Biofilm Activity for Dental Implantology Applications
}

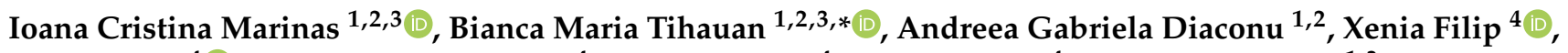 \\ Anca Petran ${ }^{4} @$, Ioana-Georgeta Grosu ${ }^{4}$, Diana Bogdan ${ }^{4}$, Lucian Barbu ${ }^{4}$, Ana Maria Ivanof ${ }^{1,3}$, \\ Marin Angheloiu 1,3, Grațiela Gradisteanu Pircalabioru 2,3(1) and Claudiu Filip ${ }^{4}$ \\ check for \\ updates \\ Citation: Marinas, I.C.; \\ 1 S.C. TEODENT SRL, Str. Lucian Blaga, No. 4, 240028 Rm. Vâlcea, Romania; \\ ioana.cristina.marinas@gmail.com (I.C.M.); dr.andreea.diaconu@gmail.com (A.G.D.); \\ ana.ivanof94@gmail.com (A.M.I.); marian.angheloiu61@gmail.com (M.A.) \\ 2 Research Institute of the University of Bucharest-ICUB, 91-95 Spl. Independentei, 50567 Bucharest, Romania; \\ gratiela87@gmail.com \\ 3 Research and Development Department of SC Sanimed International Impex SRL, \\ Șos. București-Giurgiu (DN5), No. 6, 087040 Călugăreni, Romania \\ 4 National Institute for Research and Development of Isotopic and Molecular Technologies, Str. Donat, \\ No. 67-103, 400293 Cluj-Napoca, Romania; xenia.filip@itim-cj.ro (X.F.); anca.petran@itim-cj.ro (A.P.); \\ ioana.grosu@itim-cj.ro (I.-G.G.); diana.bogdan@itim-cj.ro (D.B.); lucian.barbu@itim-cj.ro (L.B.); \\ claudiu.filip@itim-cj.ro (C.F.) \\ * Correspondence: ciubuca.b@gmail.com; Tel.: +40-733229834
}

Tihauan, B.M.; Diaconu, A.G.; Filip, X.; Petran, A.; Grosu, I.-G.; Bogdan, D.; Barbu, L.; Ivanof, A.M.; Angheloiu, M.; et al. PolydopamineAssisted Surface Modification of Ti-6Al-4V Alloy with Anti-Biofilm Activity for Dental Implantology Applications. Coatings 2021, 11, 1385. https: / /doi.org/10.3390/ coatings11111385

Academic Editor: Hideyuki Kanematsu

Received: 12 October 2021 Accepted: 9 November 2021 Published: 12 November 2021

Publisher's Note: MDPI stays neutral with regard to jurisdictional claims in published maps and institutional affiliations.

Copyright: (c) 2021 by the authors. Licensee MDPI, Basel, Switzerland. This article is an open access article distributed under the terms and conditions of the Creative Commons Attribution (CC BY) license (https:/ / creativecommons.org/licenses/by/ $4.0 /)$.

\begin{abstract}
Coating the surfaces of implantable materials with various active principles to ensure inhibition of microbial adhesion, is a solution to reduce infections associated with dental implant. The aim of the study was to optimize the polydopamine films coating on the Ti-6Al-6V alloy surface in order to obtain a maximum of antimicrobial/antibiofilm efficacy and reduced cytotoxicity. Surface characterization was performed by evaluating the morphology (SEM, AFM) and structures (Solid-state 13C NMR and EPR). Antimicrobial activity was assessed by logarithmic reduction of $\mathrm{CFU} / \mathrm{mL}$, and the antibiofilm activity by reducing the adhesion of Escherichia coli, Staphylococcus aureus, and Candida albicans strains. The release of NO was observed especially for C. albicans strain, which confirms the results obtained for microbial adhesion. Among the PDA coatings, for 0.45:0.88 $\left(\mathrm{KMnO}_{4}\right.$ :dopamine) molar ratio the optimal compromise was obtained in terms of antimicrobial activity and cytotoxicity, while the 0.1:1.5 ratio $\left(\mathrm{KMnO}_{4}\right.$ :dopamine) led to higher $\mathrm{NO}$ release and implicitly the reduction of the adhesion capacities only for C. albicans, being slightly cytotoxic but with moderate release of LDH. The proposed materials can be used to reduce the adhesion of yeast to the implantable material and thus inhibit the formation of microbial biofilms.
\end{abstract}

Keywords: polydopamine; antibiofilm activity; cytotoxicity; Ti-6Al-4V alloy

\section{Introduction}

Microbial biofilms formation on oral surfaces most frequently involves the development of caries, gingivitis, periodontitis, and in the case of dental implants, mucositis and peri-implantitis [1]. If peri-implantitis is not correctly treated, it can lead to a detrimental effect on osteointegration. The treatment is difficult, and it is an important problem in modern clinical practice. In this context, many scientific studies have focused on the development of new implantable materials to inhibit bacterial adhesion and thus reduce implant infection [2].

The surface modification of implantable device [3-6] are complex and do not have a general applicability to various materials. An easy method for changing the surface of solids by dip coating in dopamine solution was proposed by Lee et al. [7]. Dopamine 
and its catechol derivatives can oxidatively polymerize in the presence of oxygen or other oxidizing agents under alkaline conditions [8].

The formation of the PDA coatings occurs by oxidative polymerization of dopamine [9], but the effective mechanisms of PDA formation as well as a detailed structural elucidation remain fields of active research [10-12]. Despite incomplete knowledge related to fundamental aspects, the number and variety of the proposed PDA-based practical applications increases [13]. Among them, the use of polydopamine as the major component within new and more effective antimicrobial (antibacterial and/or antifungal) coatings have attracted a lot of interest [14], fully motivated by the strong adhesion of PDA to virtually any type of substrate, and by its demonstrated biocompatibility.

Polydopamine obtained under air oxidation at $\mathrm{pH}=8.5$ prohibitively long time required to produce uniform PDA films of $20-40 \mathrm{~nm}$ thickness [15] which are unrecommended for industrial applications. By using oxidizing agents like $\mathrm{Cu}_{2} \mathrm{SO}_{4}, \mathrm{NaIO}_{4}, \mathrm{KMnO}_{4}$ have been demonstrated to significantly reduce the deposition time down, and have the advantage that dopamine oxidation can be achieved over a larger $\mathrm{pH}$ range. This is important for extending the functionalization strategies that can be followed to produce efficient antimicrobial surfaces.

The progress in the PDA synthesis methodology has facilitated the proposal of numerous antimicrobial coatings built upon various types of PDA platforms, according to Kumar et al. [14]. Most of the antipathogenic applications use PDA as an intermediate layer, exploiting the strong adhesion to the substrate and the enhanced capacity of the free surface to bind various antimicrobial agents, from antibiotics [16] and antimicrobial peptides [17] to Ag nanoparticles [18]. Another approach is to exploit the antipathogenic properties of the oxidizing agent used in the PDA synthesis, or consider PDA-analogues formed by polymerization of dopamine derivatives $[19,20]$.

Other oxidizing agents used for PDA synthesis, and capable to produce species with biological activity, were not investigated so far. In this context, we studied the PDA coating obtained under $\mathrm{KMnO}_{4}$ oxidation with respect to possible antipathogenic effects. On the other hand, $\mathrm{KMnO}_{4}$ was reported [21] to determine the fastest PDA deposition rate over a wide $\mathrm{pH}$ range, which makes it very attractive from practical perspective. For this purpose, Ti-Al6-V4 alloy was used as a substrate with relevance in implantology and covered with $\mathrm{KMnO}_{4}$ oxidized PDA thin films. PDA coated substrates were prepared under various deposition conditions and then tested with respect to their potential antipathogenic effect against fungi (Candida albicans), Gram-positive (Staphylococcus aureus), and Gramnegative (Escherichia coli) bacteria. These strains were used to evaluate the full spectrum of antimicrobial activity in accordance with ISO16142-2:2017 for medical devices.

An important aspect of the microbial biofilm's formation consists in the physicochemical characteristics of the implantable material surface. Thus, previous studies revealed that PDA functionalized films showed bactericidal and antibiofilm properties through hydrophilic behavior and smooth surface that prevents bacterial adhesion and long-term survival, probably due to the negative charge surface by the presence of the carboxyl group (electrostatic repulsion between the surface and the microbial strain), the pro-oxidant character of PDA leading to intracellular damage by endogenous ROS/RNI production or inhibiting the interaction between the cell adhesions and the PDA functionalized surface [14,22-24].

Therefore, the aim of the study consists in investigating the effect of molar ration between dopamine and an oxidizing agent on the surface morphology modification of Ti-6Al-4V alloy, antimicrobial and anti-biofilm activities and cytotoxicity for composite optimization and increased compatibility between dental implant and tissue.

\section{Materials and Methods}

\subsection{Synthesis of the PDA Samples Used in Structural Investigations}

Polydopamine samples for the ss-NMR and EPR studies were prepared based on the standard procedures reported for air oxidation in basic conditions [7], $\mathrm{pH} 8.5,10 \mathrm{mM}$ 
dopamine concentration, and $10 \mathrm{mM}$ Tris buffer. The so prepared dopamine hydrochloride solution was stirred over night at room temperature under air. The resulting black precipitate was separated by centrifugation (MPW Med. instruments, Warszawa, Poland) at $4000 \times g \mathrm{rpm}$, washed with water to remove the excess of Tris and unreacted dopamine and centrifuged again. The procedure was repeated five times, after which the solid was dried in the oven overnight. The same protocol was followed when using $\mathrm{KMnO}_{4}$ as oxidizing agent, except that the buffer was selected sodium acetate when working at acidic conditions, $\mathrm{pH} 5.5$, and various $\mathrm{KMnO}_{4}$ to dopamine relative molar ratios were considered, depending on the particular aspect under investigation.

\subsection{Deposition of PDA to Ti- $6 A l-4 V$}

A series of PDA depositions onto the acid-etched Ti-6Al-4V discs (RG Tech, Xi'an RG Industry \& Technology Co. Ltd., Xi'an, China) were made, considering different molar ratios between dopamine and the oxidizing agent, $\mathrm{KMnO}_{4}$. The Ti-6Al-4V discs, $1 \mathrm{~cm}$ in diameter and $1 \mathrm{~mm}$ thick, were treated with $80 \% \mathrm{H}_{2} \mathrm{SO}_{4}$ at $60{ }^{\circ} \mathrm{C}$ under magnetic stirring to obtain a rough surface. After $30 \mathrm{~min}$ of acidic treatment, they were washed with water and ethanol and left to dry for $30 \mathrm{~min}$ in an oven at $37^{\circ} \mathrm{C}$. Coating with polydopamine was performed in Tris buffer solution $(10 \mathrm{mM}, \mathrm{pH}=8.5)$ at $30 \mathrm{~min}$ reaction time and $200 \mathrm{rpm}$. For the investigated P1-P4 samples, various relative concentrations of dopamine vs. $\mathrm{KMnO}_{4}$ were used, as specified in Table 1. The worked up of PDA-coated Ti-6Al-4V discs were performed by washing with water, sonication for $10 \mathrm{~min}$ to remove PDA aggregates from the surface and washing with ethanol followed by $24 \mathrm{~h}$ drying at $37^{\circ} \mathrm{C}$. The model response surface method (RSM) was employed, using Design Expert 13.0 program (StateEase Inc., Minneapolis, MN, USA). The quadratic response surface was used to locate the relationship between the response and every individual factor. The test of significance and analysis of variance (ANOVA) were also determined to find the fit of the model and the optimal relationship between dopamine and oxidizing agent to biological efficiency (antimicrobial and cytotoxicity).

Table 1. Two-variable design with five responses for the logarithmic microbial reduction and cytotoxicity of polydopamineassisted surface modification of Ti-6Al-4V alloy (mean \pm SD).

\begin{tabular}{|c|c|c|c|c|c|c|c|c|}
\hline Nr. & Cod & $\begin{array}{c}\text { Factor } 1 \\
\text { (Dopamine } \\
\text { Molar Echiv) }\end{array}$ & $\begin{array}{c}\text { Factor } 2 \\
\left(\mathrm{KMnO}_{4}\right. \\
\text { Molar Echiv) }\end{array}$ & $\begin{array}{l}\text { Reduction } \\
\text { of } S \text {. aureus } \\
(\operatorname{lgCFU} / \mathrm{mL})\end{array}$ & $\begin{array}{c}\text { Reduction } \\
\text { of } E \text {. coli } \\
(\operatorname{lgCFU} / \mathrm{mL})\end{array}$ & $\begin{array}{c}\text { Reduction of } \\
\text { C. albicans } \\
(\operatorname{lgCFU} / \mathrm{mL})\end{array}$ & $\begin{array}{c}\text { MTT } \\
\text { (\%Viability) }\end{array}$ & $\begin{array}{c}\text { LDH (\%LDH } \\
\text { Release) }\end{array}$ \\
\hline 1 & P1 & 0.5 & 0.1 & $0.38 \pm 0.07$ & $0.55 \pm 0.10$ & $0.38 \pm 0.06$ & $69.50 \pm 4.35$ & $24.99 \pm 3.54$ \\
\hline 2 & $\mathrm{P} 2$ & 0.5 & 0.5 & $0.58 \pm 0.10$ & $0.24 \pm 0.05$ & $0.84 \pm 0.17$ & $90.51 \pm 0.31$ & $23.04 \pm 2.35$ \\
\hline 3 & P3 & 1.5 & 0.1 & $0.33 \pm 0.02$ & $0.70 \pm 0.06$ & $0.78 \pm 0.14$ & $88.52 \pm 10.46$ & $35.31 \pm 4.13$ \\
\hline \multirow[t]{5}{*}{4} & $\mathrm{P} 4$ & 1.5 & 0.5 & $0.38 \pm 0.08$ & $0.24 \pm 0.05$ & $0.84 \pm 0.18$ & $94.31 \pm 3.65$ & 13.614 \\
\hline & & Model ( $p$-value) & & 0.0153 & $<0.0001$ & 0.0018 & 0.0039 & 0.0042 \\
\hline & & F-value & & 6.52 & 31.18 & 13.29 & 10.38 & 10.16 \\
\hline & & $R^{2}$ & & 0.7099 & 0.9212 & 0.8329 & 0.7955 & 0.7921 \\
\hline & & Adjusted $\mathrm{R}^{2}$ & & 0.6011 & 0.8917 & 0.7702 & 0.7189 & 0.7142 \\
\hline
\end{tabular}

\subsubsection{Characterization Techniques}

Scanning Electron Microscope

The morphology of the PDA films deposited on Ti-6Al-4V was imaged on a Hitachi SU8320 cold field emission scanning electron microscope (Hitachi High-Tech, Tokyo, Japan), at an accelerating voltage of $30 \mathrm{kV}$, using secondary electron detector. All the samples were attached on a stab with carbon double sticky tape. No sputter coating was used.

\section{Atomic Force Microscopy (AFM)}

AFM measurements were performed using an Asylum Cypher S microscope (Asylum Research-Oxford Instruments, Santa Barbara, CA, USA) in air using the amplitude modulated AC mode, with AC160TS-R3 probes (Olympus, Japan). Data acquisition and image 
processing was performed using the integrated Asylum Research software written within Igor Pro software package. Several areas randomly selected of the sample were analyzed at $512 \times 512$ pixels and a scan rate between 0.5 and $1 \mathrm{~Hz}$. Thickness of the polymeric layer was evaluated by scratching the film with a blunt stainless-steel needle.

\section{Solid-State ${ }^{13} \mathrm{C}$ NMR Spectrometry}

Solid-state ${ }^{13} \mathrm{C}$ NMR spectra (Bruker BioSpin, Rheinstetten, Germany) of representative PDA samples were recorded at $125.73 \mathrm{MHz}$ Larmor frequency with a Bruker AVANCE III $500 \mathrm{MHz}$ (Bruker, Billerica, MA, USA) spectrometer operating at room temperature. Standard RAMP ${ }^{13} \mathrm{C}$ CP-MAS spectra were acquired at $14 \mathrm{kHz}$ spinning frequency, with $2 \mathrm{~ms}$ contact time, and proton decoupling under TPPM, by averaging a number of transients adequate for each sample, with a recycle delay of $1 \mathrm{~s}$. The recorded ${ }^{13} \mathrm{C}$ ss-NMR spectra are calibrated with respect to the $\mathrm{CH}_{3}$ line in TMS (tetramethyl silane) through an indirect procedure which uses $\alpha$-Glycine (176.5 ppm for the ${ }^{13} \mathrm{COOH}$ line) as an external reference.

\section{Electron Paramagnetic Resonance Spectrometry (EPR)}

EPR (Bruker, Billerica, MA, USA) measurements of powder samples were carried out on a Bruker E-500 ELEXSYS X-band $(9.78 \mathrm{GHz})$ spectrometer at room temperature. The EPR spectra were recorded using equal quantities of samples.

\subsubsection{Assessment of Antimicrobial Activity}

Logarithmic Reduction

The antimicrobial activity of Ti-6Al-4V-PDA samples was determined by logarithmic and percentage reduction of reference microorganisms. Three reference strains from the American Type Culture Collection (ATCC, Manassas, VA, USA) were used for testing (S. aureus ATCC 6538, E. coli ATCC 8739, and C. albicans ATCC 10231). The samples were immersed in $0.9 \mathrm{~mL}$ of Brain Heart Infusion (BHI) for bacterial strains and Sabouraud broth for C. albicans, seeded with $0.1 \mathrm{~mL}$ of $10^{5} \mathrm{CFU} / \mathrm{mL}$ (obtained by diluting the suspension $0.5 \mathrm{McFarland}-1.5 \times 10^{8} \mathrm{CFU} / \mathrm{mL}$ for bacterial strains and $1.4 \times 10^{6}$ for C. albicans-the suspensions used were checked by plate counting method) and incubated at $37^{\circ} \mathrm{C}$ for $24 \mathrm{~h}$. After the contact with the microbial inoculum for $30 \mathrm{~min}$ and $24 \mathrm{~h}$, the discs were shaken vigorously before successive ten-fold dilutions were made and spotted in agar media plates (Muller-Hilton for bacterial strains and Sabouraud for yeast) in order to determine CFU (colony forming unit) $/ \mathrm{mL}$ after $24 \mathrm{~h}$ at $37^{\circ} \mathrm{C}$ incubation. The method was performed in triplicate

The logarithmic reduction was calculated using the formula:

$$
\text { Reduction }(\mathrm{CFU} / \mathrm{mL})=\lg \mathrm{A}-\lg \mathrm{B}
$$

where $\mathrm{A}$ is $\mathrm{CFU} / \mathrm{mL}$ of positive control (strain without material contact); $\mathrm{B}$ is $\mathrm{CFU} / \mathrm{mL}$ of samples (strain with materials).

\section{In Vitro Quantification of Reactive Nitrogen Intermediates (RNI)}

RNI was measured using a spectrophotometric assay of total nitrite content using Griess reagent according to the methodology described by Quinteros et al. [25] with some modifications. Samples were immersed in inoculated medium with microbial suspension adjusted to $10^{5} \mathrm{CFU} / \mathrm{mL}$ and incubated for $24 \mathrm{~h}$ at $37^{\circ} \mathrm{C}$. The supernatant for each sample were centrifuged at $10,000 \times g \mathrm{rpm}$ for $10 \mathrm{~min}$. Then, over $50 \mu \mathrm{L}$ of the supernatants/standard, $50 \mu \mathrm{L}$ of $2 \%$ sulfanilamide (Sigma-Aldrich, St. Louis, MO, USA) in $5 \%(v / v) \mathrm{H}_{3} \mathrm{PO}_{4}$ (Sigma-Aldrich) and $50 \mu \mathrm{L}$ of $0.1 \%$ aqueous solution of N-(1-naphthyl)ethylenediamine dihydrochloride (Sigma-Aldrich) were added. Azo dye formation was measured after $30 \mathrm{~min}$ at $\lambda=540 \mathrm{~nm}$ using FlexStation 3 (Molecular Devices Company, Sunnyvale, CA, USA). The strains used were: S. aureus, E. coli and C. albicans. We used culture media control for each strain. For the quantification of nitric oxide, a calibration 
curve was performed with $\mathrm{NaNO}_{2}$ in the range between $0-25 \mu \mathrm{M}(\mathrm{R} 2=0.9991)$. The strain control is Ti-6Al-4V alloy without PDA deposition. The experiment was performed in triplicate.

\section{Study of Antibiofilm Activity of Ti-6Al-4V-PDA Disks}

The inert surfaces represented by Ti-6Al-4V-PDA disks was tested for their capacity to inhibit bacterial adhesion. After $18-24 \mathrm{~h}$ of incubation at $36 \pm 2{ }^{\circ} \mathrm{C}$ with $10^{5} \mathrm{CFU} / \mathrm{mL}$ S. aureus ATCC 6538, E. coli ATCC 8739, and C. albicans ATCC 10,231 cultures (Brain Heart Infusion for bacterial strains and Sabouraud for yeast), the 24 wells plates containing the Ti-6Al-4V-PDA disks were emptied, washed three times with sterile distillated water and fixed with methanol for $5 \mathrm{~min}$. The sample were viewed with a Hitachi SU8320 cold field emission scanning electron microscope (Hitachi High-Tech, Tokyo, Japan), at an accelerating voltage of $30 \mathrm{kV}$, using secondary electron detector. The microbial cells adhered to the Ti-6Al-4V-PDA surfaces were stained with 1\% violet crystal solution (SigmaAldrich) for $15 \mathrm{~min}$. Subsequently, the colored biofilm was suspended in $33 \%$ acetic acid (Sigma-Aldrich) solution. The microbial adherence was assessed spectrophotometrically, by measuring the absorbance at $\lambda=490$ using FlexStation 3 (Molecular Devices Company, Sunnyvale, CA, USA). The results were express as percentage from total adherence of strain control (Ti-6Al-4V alloy without coating). The experiment was performed in triplicate.

\subsubsection{Determination of Cytotoxicity}

The MC3T3-E1 osteoblastic cell line from Mouse C57BL/ 6 calvaria and human gingival fibroblasts (ECACC-European Collection of Authenticated Cell Cultures, Manassas, Virginia, USA) were selected as models for intracellular toxicity assessment of Ti-6Al-4VPDA disks.

Cells were cultivated in DMEM (Dulbecco's Modified Eagle Medium, Sigma-Aldrich) media supplemented with 10\% FBS (Fetal Bovine Serum-Sigma-Aldrich) and 1\% Pen/Strep (penicillin/streptomycin solution, $50 \mu \mathrm{g} / \mathrm{mL}$-Sigma-Aldrich) for $24 \mathrm{~h}$ at $37^{\circ} \mathrm{C}, 95 \%$ humidity with $5 \% \mathrm{CO}_{2}$. After $24 \mathrm{~h}$ cells were washed with PBS (Phosphate Buffered SolutionSigma-Aldrich), harvested using trypsin (Sigma-Aldrich) and counted using Trypan Blue (Sigma-Aldrich) and a hemocytometer. The seeding density for the MTT and LDH assays was optimized at $5 \times 10^{4}$. The Ti-6Al-4V-PDA disks were placed into 24 wells plated, and the harvested cells were dispersed on top, and incubated for $24 \mathrm{~h}$ at $37^{\circ} \mathrm{C}, 95 \%$ humidity with $5 \% \mathrm{CO}_{2}$.

Using the MTT (3-(4,5-dimethylthiazol-2-yl)-2,5-diphenyltetrazolium bromide) assay we evaluated the cellular metabolic activity, cell viability and cytotoxicity of disks. The basic principle of this method relies on the reduction of a yellow tetrazolium salt to purple formazan crystals by metabolically active cells.

After $24 \mathrm{~h}$ of exposure to Ti-6Al-4V-PDA disks, cells were incubated for $4 \mathrm{~h}$ with MTT reagent (Roche) at $37{ }^{\circ} \mathrm{C}, 95 \%$ humidity with $5 \% \mathrm{CO}_{2}$. After incubation, cells were treated with MTT solvent (Roche) for $15 \mathrm{~min}$ at room temperature. Absorbance was measured using FlexStation 3 (Molecular Devices Company, Sunnyvale, CA, USA) at $\lambda=570 \mathrm{~nm}$. The experiment was performed in triplicate.

For LDH assessment cells were prepared and treated alike as for the MTT assay. We chose LDH assay for the assessment of cell death by quantification of plasma membrane damage. An increased enzyme activity in the supernatant directly correlates with the amount of formazan formed, and accordingly to the number of lysed cells. With the LDH Cytotoxicity Detection Kit (Roche), LDH activity was measured in culture supernatants using FlexStation 3 (Molecular Devices Company, Sunnyvale, CA, USA) at $\lambda=492 \mathrm{~nm}$ with a $\lambda=600 \mathrm{~nm}$ wavelength reference. The experiment was performed in triplicate

\subsection{Statistical Analysis}

Data were expressed as means \pm SD determined by triplicate analysis. The statistical analysis was done using GraphPad Prism 9. Data were analyzed using unpaired $t$ test with 
Welch correction of multiple comparisons for antibiofilm activity and NO release. The level of significance was set to $p<0.05$.

\section{Results}

\subsection{Structural and Morphological Characterization}

Solid-state NMR and EPR investigations were performed with the purpose of comparing the major structural features of PDA formed under $\mathrm{KMnO}_{4}$ oxidation with those found in the material obtained by conventional air oxidation [7]. Figure 1, compares the ${ }^{13} \mathrm{C}$ ss-NMR spectra recorded on three different PDA samples: (a) oxidative polymerization of dopamine hydrochloride (10 $\mathrm{mM}$ aqueous solution) under air at $\mathrm{pH}=8.5$, using the Tris buffer; (b) polymerization of dopamine hydrochloride (10 $\mathrm{mM}$ aqueous solution) at $\mathrm{pH}=8.5$ by using $\mathrm{KMnO}_{4}$ as oxidation agent at 0.4 molar ratio relative to dopamine, in TrisCl buffer; (c) the same conditions as previously, except for the $\mathrm{KMnO}_{4}$ /dopamine molar ration, which was lowered to 0.05 .

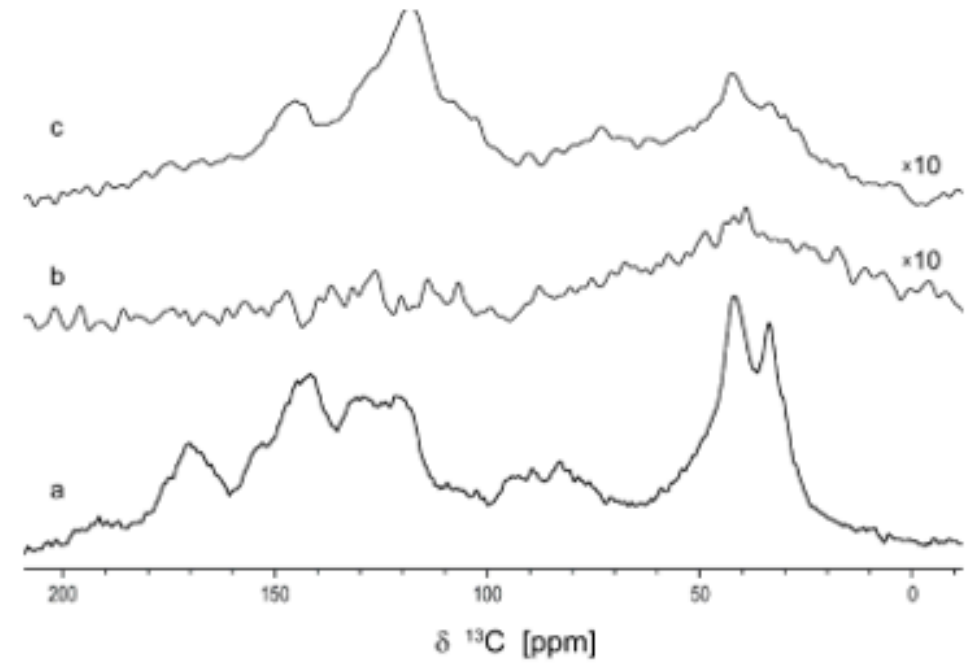

(A)

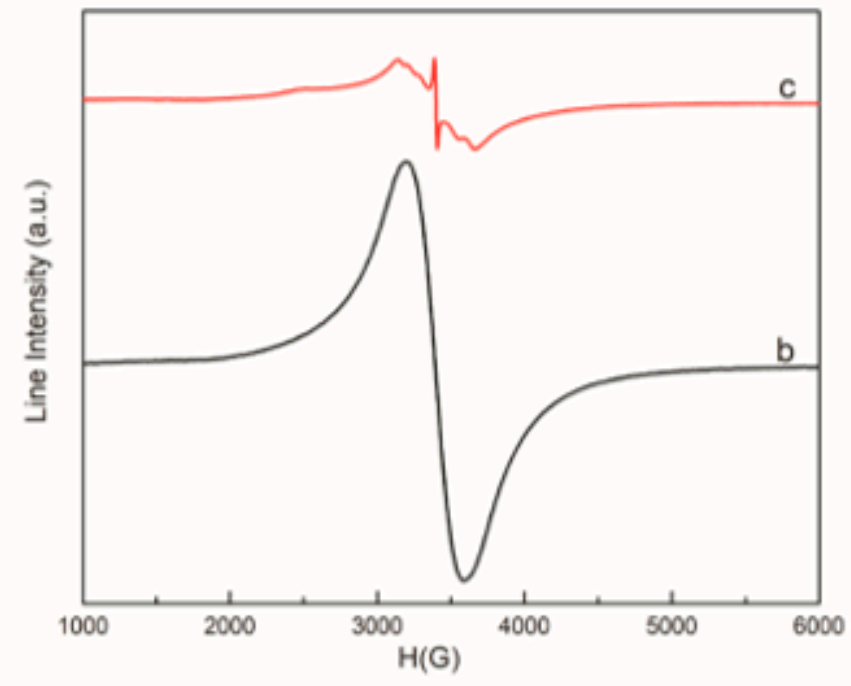

(B)

Figure 1. (A) Solid-state ${ }^{13} \mathrm{C}$ NMR spectra recorded on three different PDA samples, as described in the text. The spectral intensities of the sample (b) and (c) are magnified ten times compared to sample (a). (B) EPR spectra of the (b) and (c) samples. 
The spectrum of the sample (a) shows all the major ss-NMR peaks characteristic to PDA: the ethylamine aliphatic carbons at 34 and 42 ppm, aromatic catechol carbons at 121 and 129 ppm, the catechol -COH carbons at 143 ppm, carbonyl at 171 ppm, and also some minor shoulders to these peaks, associated with the cyclized indole/indoline units, as detailed in [12]. By contrast, the spectrum recorded on sample (b) barely shows a severely broadened peak in the aliphatic spectral region, centered around $40 \mathrm{ppm}$, but no signals at all could be detected in the aromatic and carbonyl regions, even though there were ten times more transients accumulated on this sample $(150 \mathrm{k})$ compared to sample (a), $15 \mathrm{k}$. We ascribe the observed dramatic drop in spectral sensitivity and resolution to the magnetic field in homogeneities across the sample due to some paramagnetic products of dopamine oxidation by $\mathrm{KMnO}_{4}$, most probably paramagnetic manganese oxides such as $\mathrm{MnO}_{2}$ and/or $\mathrm{Mn}_{2} \mathrm{O}_{3}$. The assumption is supported by the spectrum obtained on the sample (c): the much lower amount of $\mathrm{KMnO}_{4}$ used in this case for oxidation leads to a reduced concentration of the generated manganese paramagnetic centers inside the final material, which partially recovers a typical PDA ${ }^{13} \mathrm{C}$ ss-NMR spectrum, though it still has much lower intensity and poorer resolution than that recorded on the sample (a).

This, however, is only an indirect, qualitative, proof. More directly, the presence of Mn paramagnetic species inside the PDA samples obtained by $\mathrm{KMnO}_{4}$ oxidation can be concluded from the EPR spectra, see Figure 1B. The spectrum of sample (b) is dominated by a broad $(390 \mathrm{G})$ line at $\mathrm{g}=2.01$, which is different from the typical EPR line reported on PDA, where the measured resonance is assigned to a superposition between $\mathrm{C}$ and $\mathrm{O}$ (semiquinone) organic radicals, at $\mathrm{g}=2.003$, and with much smaller linewidth, of only about $15 \mathrm{G}$ [26]. By lowering eight times the $\mathrm{KMnO}_{4}$ concentration in the sample (c), a more complex EPR spectrum is observed. This signal is generated by the superposition of three signals: (i) the narrow line due to PDA, (ii) a hyperfine spitting with $\mathrm{A}=89 \mathrm{G}$ specific to isolated Mn ions [27] and (iii) a broad line with lower intensity, most probably due to a minor fraction of Mn ions in strong dipolar interaction, similar to sample (b).

The quality of the PDA films with $\mathrm{KMnO}_{4}$ as oxidation agent was investigated by Atomic Force Microscopy (AFM) on samples prepared under two distinct conditions, considered representative for the whole series of PDA coatings discussed in the present work. The acid-etched Ti-6Al-4V substrates are inappropriate for such studies, especially for film thickness measurements, so that glass cover slips substrates were used instead as model systems. The results are synthetically illustrated in Figure 2. The most important conclusions that can be drawn from the analysis are the following: (i) the fast dopamine oxidation by $\mathrm{KMnO}_{4}$ gives rise to uniform PDA coating of the substrate within one hour deposition time on a large $\mathrm{pH}$ range, from 5.5 to 8.5, i.e., the two cases investigated here; (ii) the thickness of the film is lower at acidic conditions $(\sim 10 \mathrm{~nm})$ than at basic $\mathrm{pH}$, ( $20 \mathrm{~nm}$ ); (iii) the number and sizes of the PDA aggregates formed in solution and trapped on the flat surface of the PDA film are relatively small, obviously benefiting from the short deposition time. Overall, one can conclude from the AFM study, that a uniform coverage was obtained with a thin (10-20 nm) and flat PDA film, which is mechanically stable attached to the substrate (no detachment was observed after 30 min ultrasonication), and we assume the same properties are preserved also when deposition is done onto the rough Ti-6Al-4V acid-etched surfaces.

Finally, the morphology of the PDA films deposited onto the acid-etched Ti-6Al-4V substrates was investigated by Scanning Electron Microscopy (SEM). The formation of the PDA film is evidenced in Figure 3 by the slight smoothening of the sharp edges carved in the non-coated material by acid etching-compare the top and bottom panels in the figure. The fact that these sharp features are not made even smoother by PDA coating is most probably due to the relatively small thickness of the deposited film, only about $20 \mathrm{~nm}$, found from the AFM measurements for the considered oxidation conditions. Additionally, the PDA coating of the substrate is further proved by the small PDA aggregates trapped onto the surface, which can be most clearly seen in the bottom-right panel of Figure 4, and also identified in the AFM images (Figure 2). 

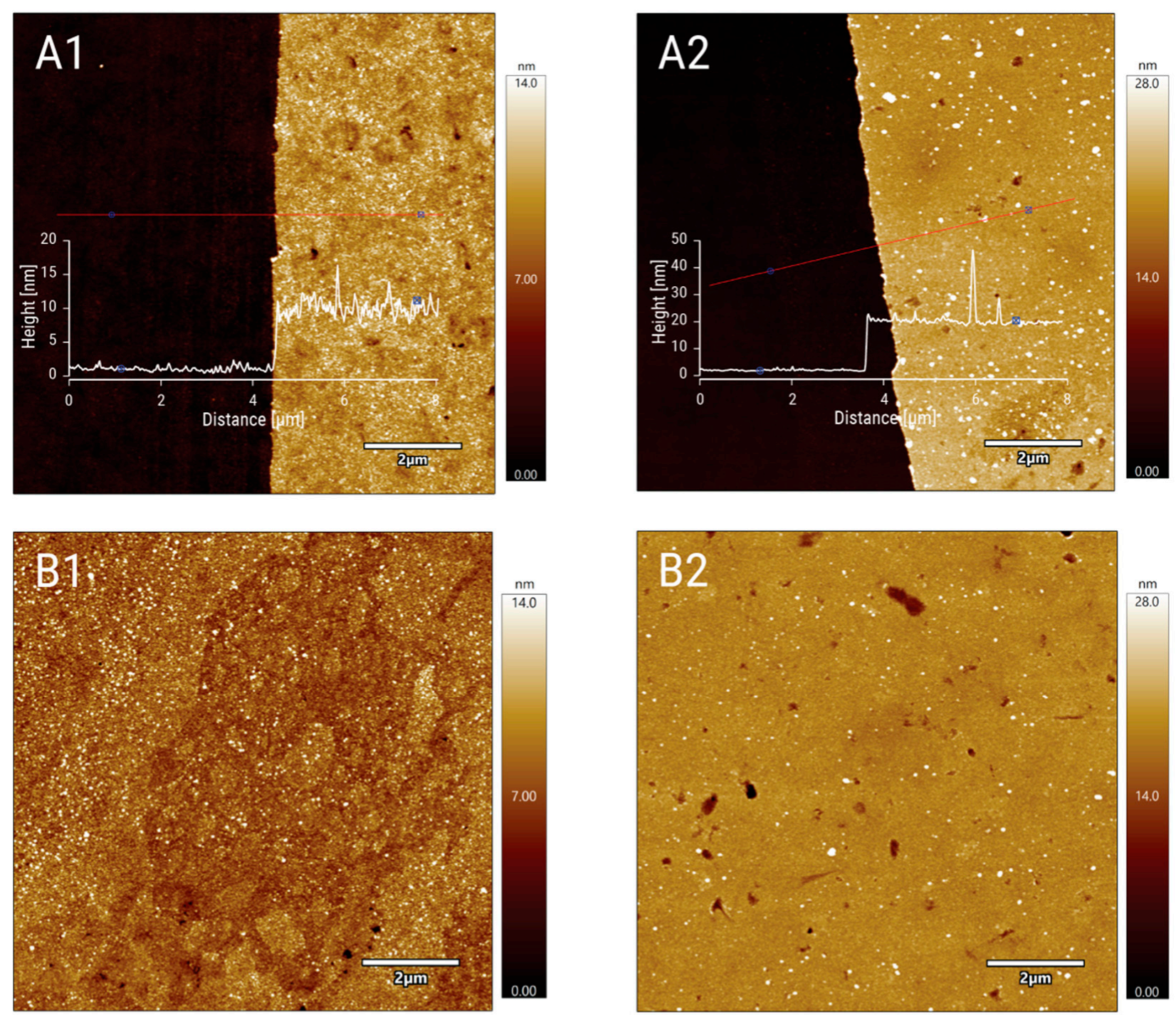

Figure 2. AFM 2D topographic images of PDA coated glass cover slips at the edge of the scratch, together with a section cut/profile along the red line (panels A), and morphology of the uniform layer far away from the scratch, respectively (panels B). The PDA films were formed by dopamine oxidation with $\mathrm{KMnO}_{4}$, for one hour reaction time under constant stirring at $200 \mathrm{rpm}$ of the reaction vials, at $\mathrm{pH}=5.5$ (left panels) and $\mathrm{pH}=8.5$ (right panels). Scan area $10 \times 10 \mu \mathrm{m}^{2}$.

\subsection{Experimental Design for Optimal Logarithmic Microbial Reduction with Low Cytotoxicity}

An optimal film design was obtained using the Response Surface Methodology (RSM) with the aim of identifying the interactions between the parameters such as molar equivalents of dopamine (0.5-1.5) and oxidizing agent (0.1-0.5) to obtain a compromise between maximum antimicrobial activity with minimal cytotoxicity.

The Design of Experiments (DOE) showed 12 experimental runs which are presented in a randomized manner in Table 1.

ANOVA analysis was performed for each experimental unit, where the quadratic model was found to be significant $(p<0.05)$. Table 1 shows ANOVA results and the statistical description for the model obtained in each response. The relationships between the dependent variables (microbial viability, eukaryotic cell viability and LDH release) and the independent variables (molar ratio $\mathrm{KMnO}_{4}$ : dopamine) are expressed by the following regression equations:

The antimicrobial activity against $S$. aureus model is given below in Equation (1)

$$
\log _{10}(\mathrm{CFU} / \mathrm{mL})=-0.3956-0.0642 \mathrm{~A}+0.0596 \mathrm{~B}-0.0322 \mathrm{AB},
$$


The antimicrobial activity against E. coli model is given below in Equation (2)

$$
\log _{10}(\mathrm{CFU} / \mathrm{mL})=-0.4181+0.0272 \mathrm{~A}+0.2062 \mathrm{~B}-0.0272 \mathrm{AB}
$$

The antimicrobial activity against C. albicans model is given below in Equation (3)

$$
\log _{10}(\mathrm{CFU} / \mathrm{mL})=-0.1763+0.0776 \mathrm{~A}+0.0962 \mathrm{~B}-0.0797 \mathrm{AB}
$$

The \% cell viability model is given below in Equation (4)

$$
\mathrm{MTT}=85.71+5.70 \mathrm{~A}+6.7 \mathrm{~B}-3.81 \mathrm{AB},
$$

The release LDH is given below in Equation (5)

$$
1 /(\mathrm{LDH})=0.0474+0.0052 \mathrm{~A}+0.0128+0.0112 \mathrm{AB},
$$

where $\mathrm{A}-$ molar equivalent of dopamine and $\mathrm{B}$-molar equivalent of $\mathrm{KMnO}_{4}$.
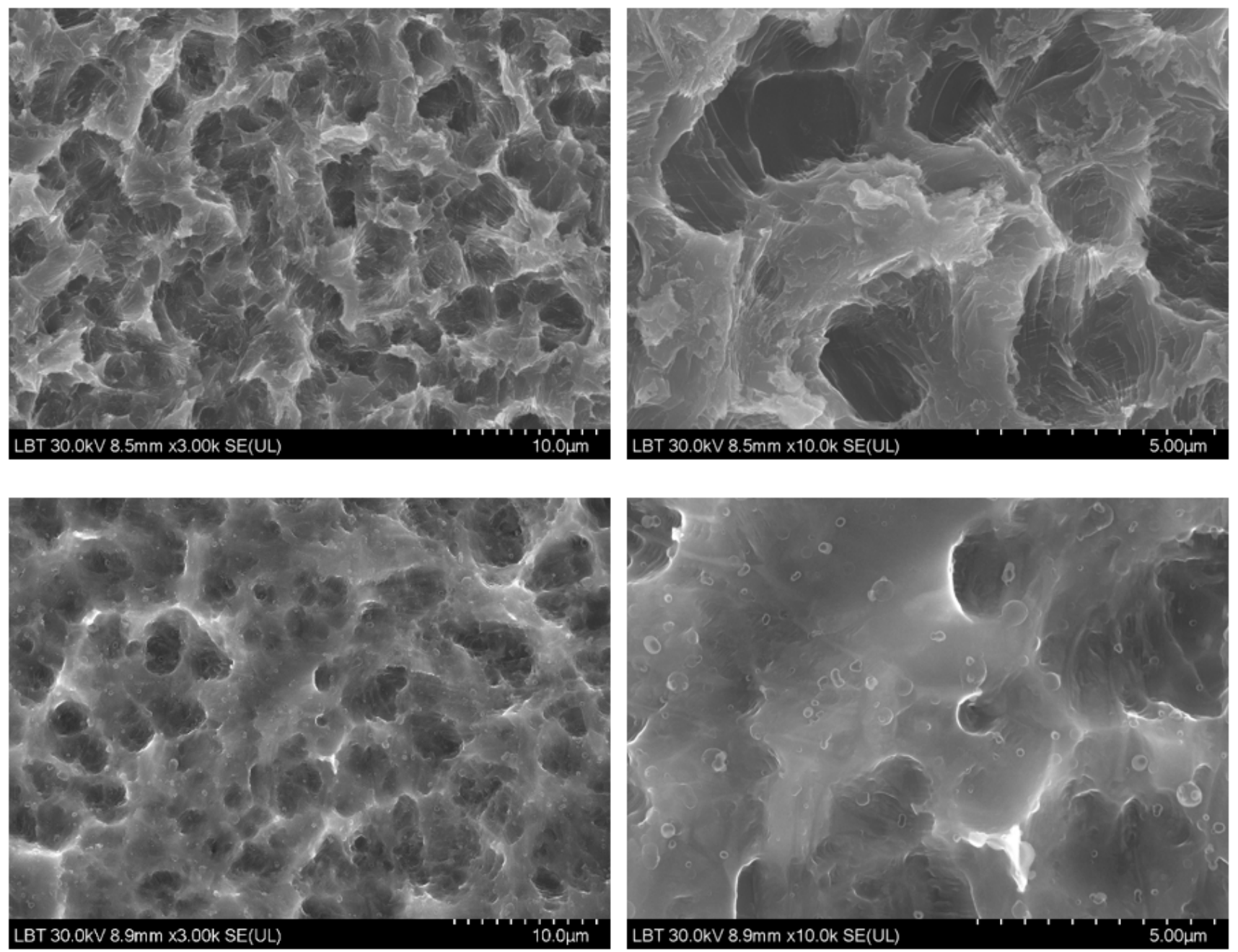

Figure 3. Comparison between SEM images of bare acid-etched Ti-6Al-4V substrates (top panels) and PDA coted substrates (bottom panels), at two different magnifications, $3 \mathrm{k}$ (left) and 10k (right), respectively. The PDA coating was obtained by dopamine oxidation with $\mathrm{KMnO}_{4}$, for one hour reaction time under constant stirring at $200 \mathrm{rpm}$ of the reaction vials, at $\mathrm{pH}=8.5$. 


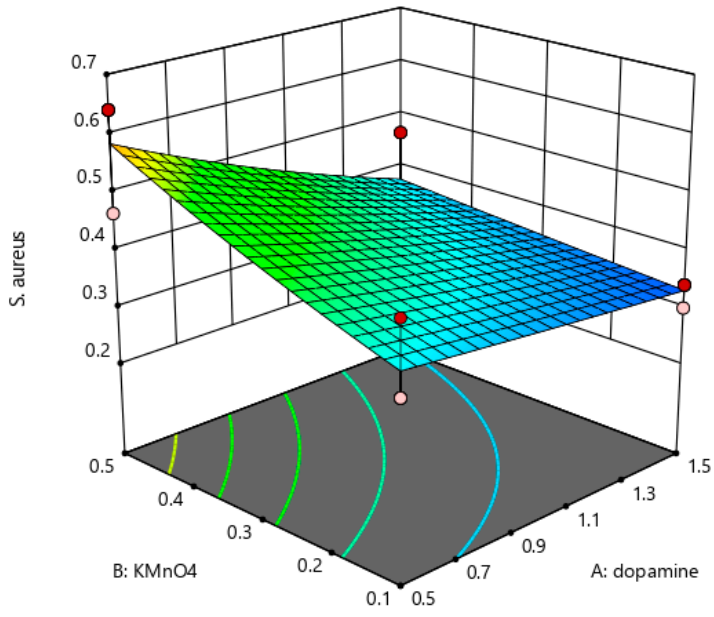

(a)

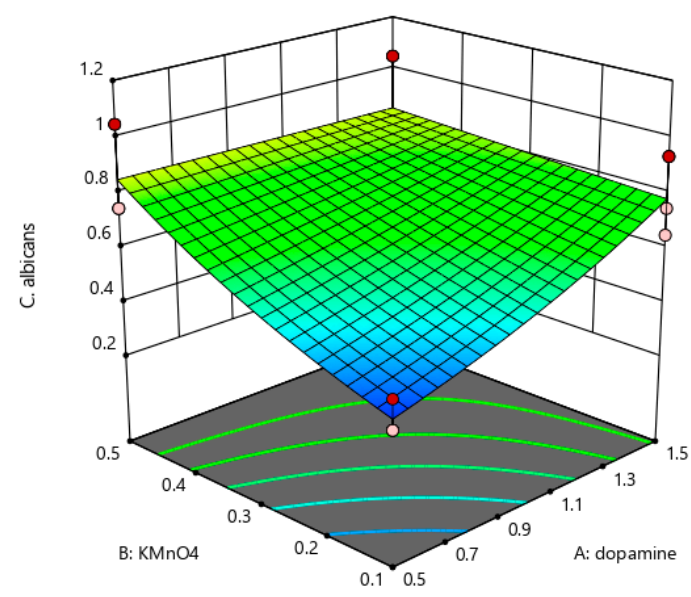

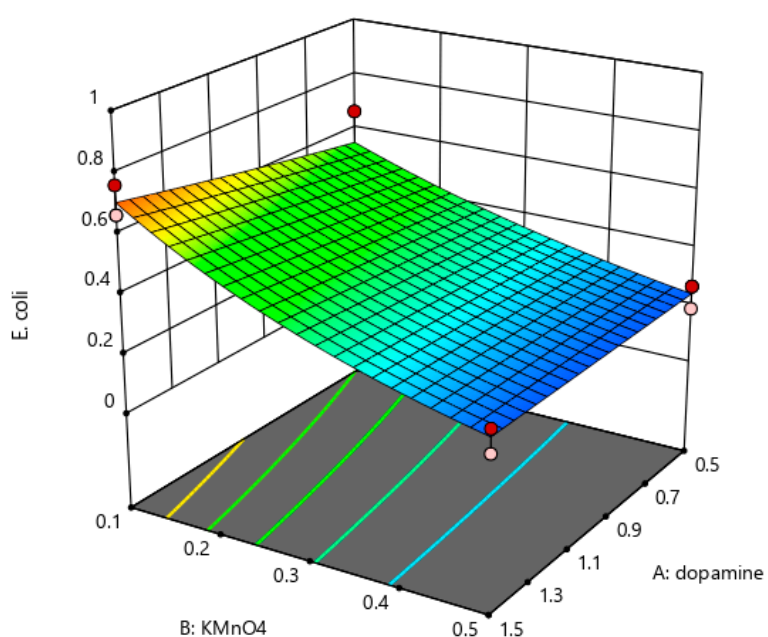

(b)

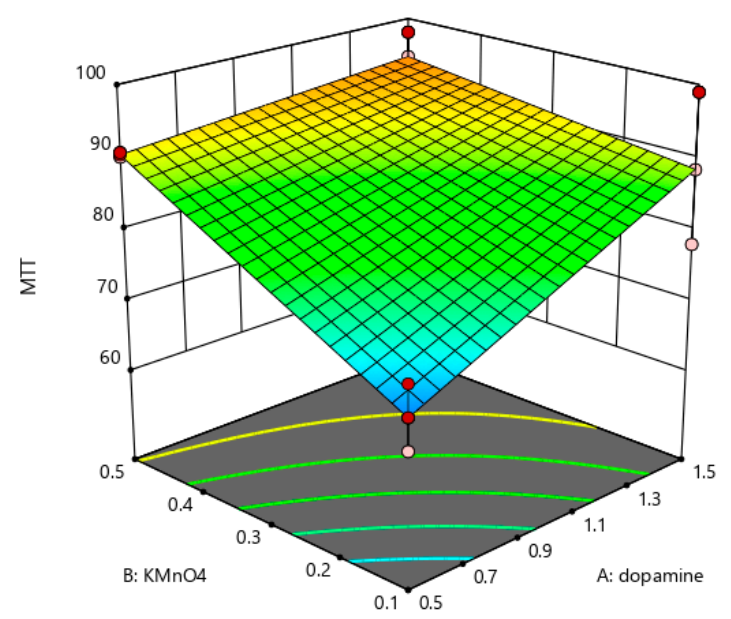

(c)

(d)

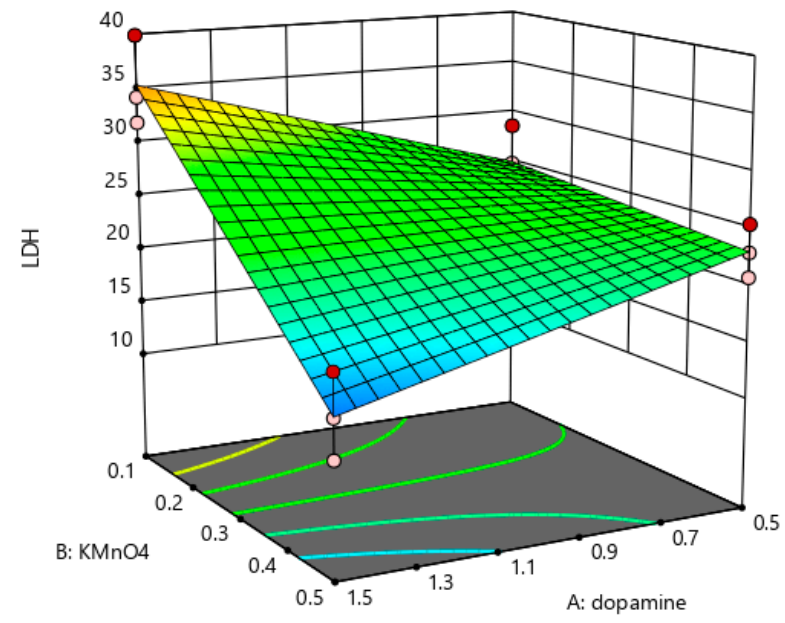

(e)

Figure 4. 3D interaction plot between dopamine and $\mathrm{KMnO}_{4}$ for (a) reduction of $\lg \mathrm{CFU} / \mathrm{mL}$ for $\mathrm{S}$. aureus strain, (b) reduction of $\mathrm{lg} \mathrm{CFU} / \mathrm{mL}$ E. coli strain, (c) reduction of $\lg \mathrm{CFU} / \mathrm{mL}$ C. albicans strain, (d) eukaryotic cell viability $\%$ and (e) \%LDH release. 
All models obtained had a statistically significant value $(p<0.05)$. The coefficient of determination $\left(\mathrm{R}^{2}\right)$ indicates the correlation between experimental and predicted data. In addition, adjusted $R^{2}$ and $R^{2}$ corroborate the significance of the models. According to the coefficients of each effect analyzed, the concentration of $\mathrm{KMnO}_{4}$ has greater effect on the all responses, but for \% cell viability and \% LDH release the effect was almost similar with dopamine concentration.

Additionally, Figure 4a-e shows the response surfaces with greater significance for the $\mathrm{CFU} / \mathrm{mL}$ logarithmic reduction of S. aureus, E. coli, C. albicans, \% cells viability and \%LDH release using the interactions between those two variables (dopamine- $\mathrm{A}$ and $\mathrm{KMnO}_{4}-\mathrm{B}$ ). Figure $4 \mathrm{a}, \mathrm{b}$ show that when increasing the concentration of oxidizing agent, the antimicrobial activity increases for E. coli and S. aureus strain, hence, this image suggests that the logarithmic reduction of $\mathrm{CFU} / \mathrm{mL}$ was not influenced by the dopamine. But, for C. albicans (Figure 4c) was observed that the logarithmic reduction of dopamine was similar with oxidizing agent, perhaps by a synergistic effect. Figure $4 \mathrm{~d}$,e shows that total cytotoxicity is generated by $\mathrm{KMnO}_{4}$ concentration.

Based on the statistical analysis obtained, Table 2 shows the limits and importance of each parameter as well as the optimal values of the parameters with the predicted responses for each response.

Table 2. Restrictions and optimal conditions predicted from the model obtained.

\begin{tabular}{ccccccc}
\hline Parameter & $\begin{array}{c}\text { Lower } \\
\text { Limit }\end{array}$ & $\begin{array}{c}\text { Upper } \\
\text { Limit }\end{array}$ & Goal & Importance & $\begin{array}{c}\text { Optimal } \\
\text { Value }\end{array}$ & $\begin{array}{c}\text { Predicted } \\
\text { Value }\end{array}$ \\
\hline $\begin{array}{c}\text { Dopamine } \\
\text { KMnO }\end{array}$ & 0.5 & 1.5 & & 3 & 0.88 & - \\
$\begin{array}{c}\text { Reduction log } \\
\text { CFU/mL S. aureus }\end{array}$ & 0.1 & 0.5 & & 3 & 0.45 & - \\
$\quad \begin{array}{l}\text { Reduction log } \\
\text { CFU/mL E. coli } \\
\text { reduction log }\end{array}$ & 0.19 & 0.64 & Maximize & 4 & & 0.47 \\
$\begin{array}{c}\text { CFU/mL C. albicans } \\
\text { \% Viability }\end{array}$ & 0.34 & 1.05 & Maximize & 4 & & 0.27 \\
$\%$ LDH release & 10.13 & 99.00 & Maximize & 5 & & 0.78 \\
\hline
\end{tabular}

\subsection{Antibiofilm Activity}

The antibiofilm activity of the PDA/Ti-6Al-4V composites were evaluated by scanning electron microscopic imaging at the magnification of $10,000 \times$ and spectrophotometrically assay (Figure 5) by purple crystal stained.

The antibiofilm activity evaluated by spectrophotometrically method showed the inhibitory influence on the microbial biofilm's development of S. aureus ATCC 6538, E. coli ATCC 8739 and C. albicans ATCC 10321. In the case of S. aureus, P1 and P3 samples showed antibiofilm activity with a statistically significant difference than control strain $(p<0.01)$. From Figure 5 it can be seen that in the case of $E$. coli the antibiofilm activity is not significant compared to the strain control while $C$. albicans had the best reduced microbial adhesion capacity for all 4 variants. Sample encoded P3 $\left(\mathrm{KMnO}_{4}\right.$ : dopamine 0.1:1.5) had the strongest activity, thus it can be concluded that the effect is generated by the increase of the polydopamine concentration. The mechanism involved in inhibiting the formation of microbial biofilms are inhibition of adhesion production or/and increased nitrosative stress with NO release [28].

The results obtained by spectrophotometrically method were in accordance with SEM data. In the case of $C$. albicans, it was observed that the polydopamine coating of the alloy discs prevents the cells adhesion, and are not dependent on the oxidizing agent concentration used. For E. coli strain, the colonies development is observed neither on the alloy disk nor on the discs covered with polydopamine. S. aureus colonized both the control disc and the polydopamine-coated discs. The levels of RNI were decreasing for bacterial cell while yeast cell increase after $3 \mathrm{~h}$ of incubation with PDA (Figure 6). The 
highest NO production was observed for S. aureus cells. For C. albicans strain an increase of RNI was observed.

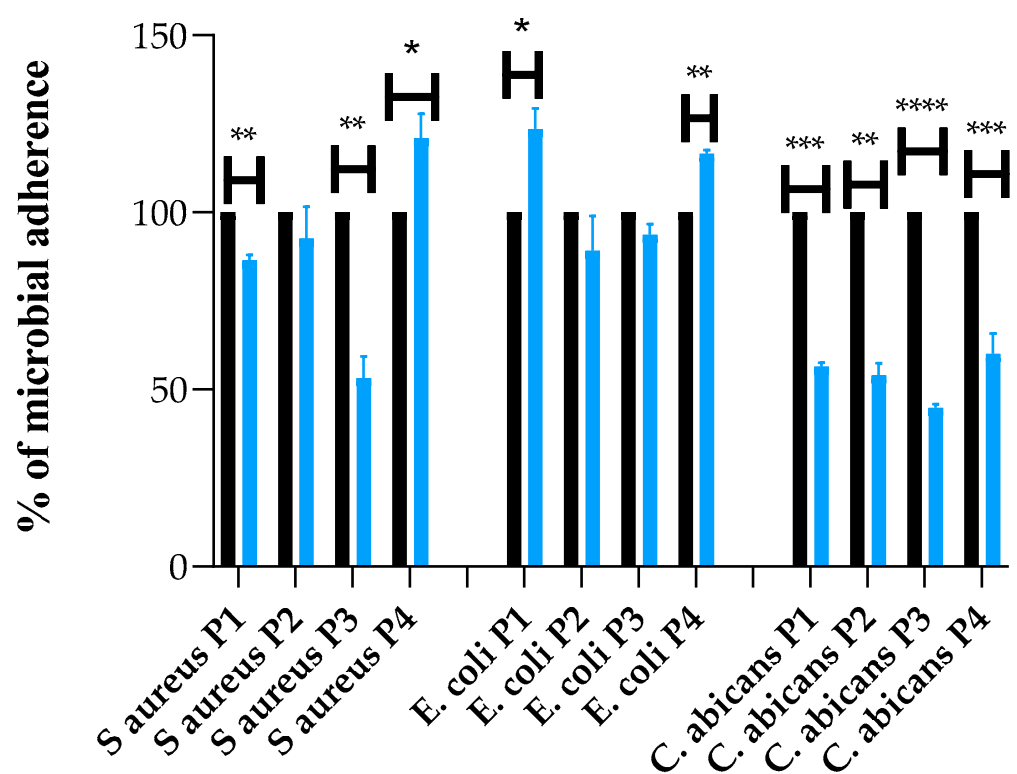

control

Figure 5. Inhibition of microbial adhesion (\%) related to the control strain (alloy without PDA coating); ${ }^{*} p<0.05,{ }^{* *} p<0.01,{ }^{* * *} p<0.001,{ }^{* * * *} p<0.0001$.

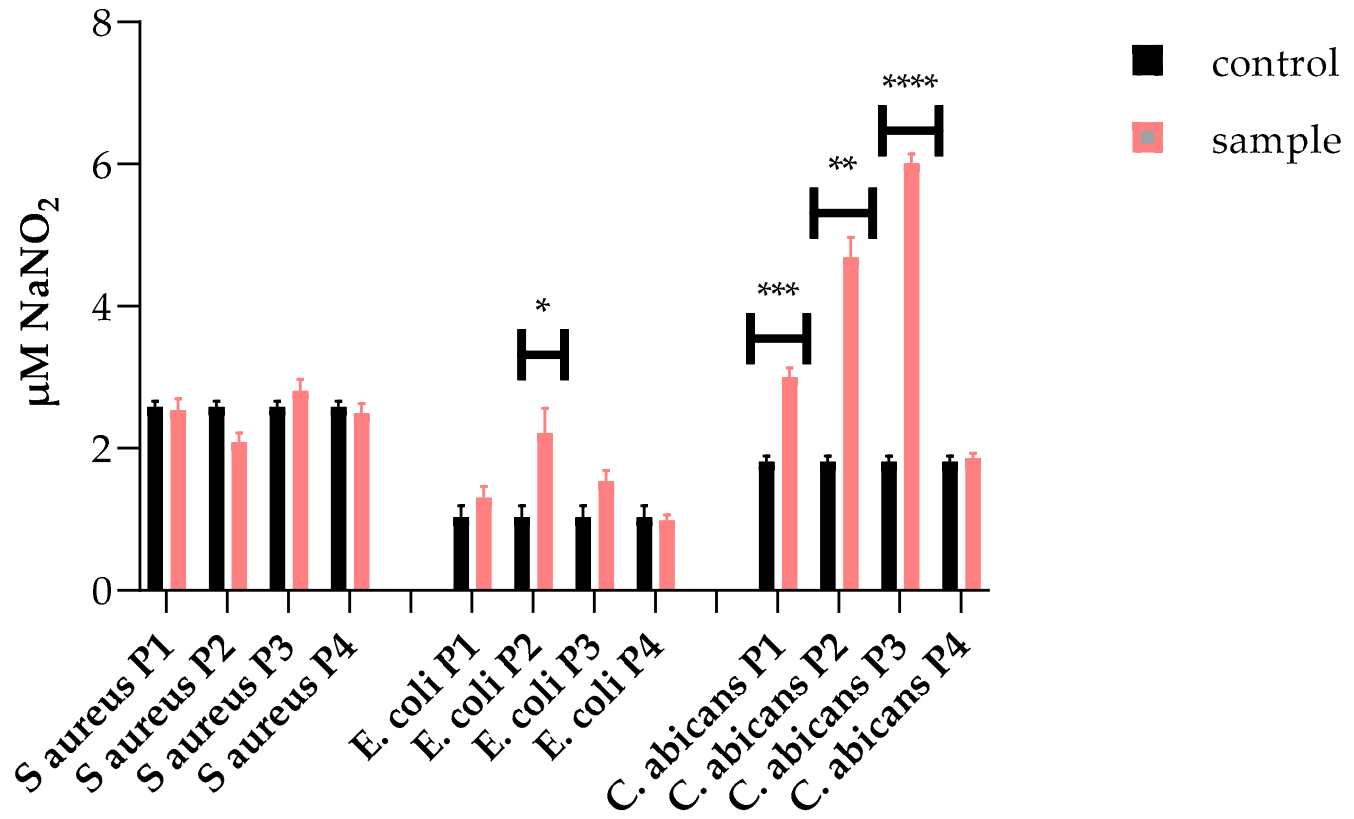

Figure 6. Extracellular RNI determined by Griess reaction for S. aureus, E. coli and C. albicans. Significance values shown in figures are: ${ }^{*} p<0.05,{ }^{* *} p<0.01,{ }^{* * *} p<0.001,{ }^{* * * *} p<0.0001$ ).

The production of detectable amounts of extracellular RNI (NO) by C. albicans, inhibited the adherence on implantable devices coating with PDA, these results were correlated with quantitative (crystal violet) and qualitative (SEM) assays for antibiofilm activity. So, by increasing the concentration of NO released, the adhesion capacity of microbial cells decreases. 


\section{Discussion}

The presence of polydopamine and oxidative paramagnetic products highlighted on the surface of the Ti-6Al-4V alloy was identified by solid-state NMR and EPR, results in accordance with previous publications [26,29]. Mn oxides have been found to have both antimicrobial and antibiofilm activity and low cytotoxicity [30]. According to Singh et al. [14], polydopamine can immobilize and ensure a prolonged release of active principles such as Mn oxides embedded between the alloy and the polydopamine film. The surface area of the polydopamine film was evaluated by SEM and AFM. Among the surface properties that influence bacterial adhesion and the subsequent formation of the biofilm, surface roughness plays a major role that goes beyond the importance of surface free energy and hydrophobicity [30].

The PDA/Ti-6Al-4V coatings have a relatively rough surface, and the presence of PDA coating was observed according to Figures 2 and 3. According to Katsikogianni et al. [31], this type of surface favors the microbial biofilms formation, an effect highlighted in the case of E. coli and S. aureus strains (Figure 5). Polydopamine is known for self-polymerizing dopamine to form surface-adherent nanocoating on a wide range of materials [7]. Moreover, excellent biocompatibility and versatile secondary reactions stimulate PDA coating in various uses [32,33].

Due to the bacteria invasion on the medical devices surface, an antimicrobial-agent coating or surface modification is imperative to maintain hygiene for dental implants and to prevent subsequent infection. Dental implants are medical devices commonly used worldwide, and can cause acquired nosocomial infections [34]. In this context, we evaluated the antimicrobial capacity through the logarithmic reduction of the CFU on the materials surface. The strains used to determine antimicrobial activity are those recommended by European standards for assessing the recovery rate of microorganisms for implantable medical devices.

As shown in Table 1 and Figure 4 the reduction of $\lg \mathrm{CFU}$ for $C$. albicans was more pronounced than the bacterial strains. In addition, the logarithmic reduction was better for variants with a higher $\mathrm{KMnO}_{4}$ content.

Although the microbial logarithmic reduction of the samples was moderate, the final biomedical application of the discs should be considered. The intended use of these is in the form of implantable medical devices. Thus, their antimicrobial properties are necessary only until the systemic treatment with antibiotics takes effect (approx. $4-5 \mathrm{~h}$ from the time of implantation). Therefore, their increased biocompatibility is a much more important and desirable parameter. This result is in accordance with Feng et al. [35].

The evaluation of the biocompatibility degree was performed on a line of murine osteoblasts, using two methods, MTT and LDH. Thus, both the cellular metabolism and the integrity of the cell membranes were evaluated after exposure to the samples represented by the substrates coated with polydopamine-based composites. The results obtained indicated good biocompatibility values for samples $\mathrm{P} 2, \mathrm{P} 3$, and $\mathrm{P} 4$ against the positive control. The treatment applied to the materials or any by-products released into the environment from their surface did not significantly influence the viability of murine osteoblasts.

Using the Experimental Design (RSM) helped us to optimize the construction of coatings with maximum antimicrobial properties but minimum cytotoxicity for dental implantology applications. For this purpose, a process for optimizing the surface modification of Ti-6Al-4V alloy was performed, starting from an initial process of PDA synthesis in the presence of an oxidizing agent. The model allowed the optimization of PDA film synthesis and the antimicrobial activity and cytotoxic effect were evaluated. The results showed that the formula that gave the best antimicrobial activity with reduced cytotoxicity was PDA film synthesis in molar ratios of 0.45:0.88 $\left(\mathrm{KMnO}_{4}\right.$ : dopamine).

The initial attachment of microbial strains to the implanted medical devices surface is the first stage in biofilm formation. Thus, the inhibition of microbial colonization using antimicrobial coatings, particularly during the most susceptible first $4 \mathrm{~h}$ period after implantation, is a fundamental strategy to prevent biofilm formation [36,37]. According to 
Sadrearham et al. [38], PDA coatings possess low-fouling and nitric oxide (NO)-releasing capabilities which are closely related to induce microbial dispersal and killing, besides preventing microbial attachment to surfaces $[39,40]$. This could be one of the explanations for the antibiofilm effect of PDA film. The PDA can alter cellular functions associated with oxidative metabolism, thus stimulating the production of RNI in planktonic microbial physiology, thus inhibiting the development of microbial biofilms without introduction a NO-releasing agent [28]. We evaluated the ability of microorganisms to release NO as a possible antifungal mechanism [41] for PDA antibiofilm activity. The PDA could cause cellular stress inside the planktonic cells, thereby affecting the microbial adhesion and growth under different conditions. These radical oxidizers could then accumulate in an extracellular medium and affect the cellular metabolism.

These results contribute to a better understanding of the antibiofilm mechanism against fungal strains in presence of PDA, which may help to clarify the relevance of PDA on biofilm formation on medical devices.

\section{Conclusions}

By ratio variations of dopamine hydrochloride and $\mathrm{KMnO}_{4}$, a compromise variant was obtained for a better antimicrobial activity with low cytotoxicity. Theoretically, the sample with molar ratio of 0.45:0.88 $\left(\mathrm{KMnO}_{4}\right.$ :dopamine) showed the best antimicrobial activity, but has a moderate cytotoxicity compared to the other samples. One of the mechanisms involved in antibiofilm activity is the ability of C. albicans to release extracellular nitric oxides.

Among the microorganisms tested, the antibiofilm effect on C. albicans was significant. C. albicans is the most common fungus in the oral cavity, and its appearance is strongly associated with stomatitis. Up to $67 \%$ of all dental implant holders are affected by candidiasis $[42,43]$. Therefore, the eradication of fungal adhesion and thus the formation of fungal biofilms on the dental implant could minimize the prevalence of oral candidiasis and dental implant failure. However, for more in-depth studies, clinicals isolated from the oral cavity will be considered for testing the optimal molar ratio dopamine: $\mathrm{KMnO}_{4}$ deposition.

Author Contributions: Conceptualization, I.C.M., C.F. and B.M.T.; methodology, I.C.M., B.M.T., C.F. and X.F.; software, I.C.M.; investigation, I.C.M., B.M.T., A.G.D., A.P., I.-G.G., D.B., L.B., A.M.I., M.A. and G.G.P.; resources, M.A. and C.F.; writing-original draft preparation, I.C.M. and C.F.; writing-review and editing, B.M.T. and G.G.P.; supervision, C.F. and A.M.I. All authors have read and agreed to the published version of the manuscript.

Funding: This research was funded by the Ministry of Research, Innovation and Digitalization; grant number POC P_40_404, SMIS 105533.

Institutional Review Board Statement: Not applicable.

Informed Consent Statement: Not applicable.

Data Availability Statement: Not applicable.

Acknowledgments: The contribution of Adriana Popa in the EPR characterization is gratefully acknowledged. Acknowledgments to Lucia Diana Ivanof for good management and supervision of research project POC P_40_404, SMIS 105533.

Conflicts of Interest: The authors declare no conflict of interest.

\section{References}

1. Ghensi, P.; Bettio, E.; Maniglio, D.; Bonomi, E.; Piccoli, F.; Gross, S.; Caciagli, P.; Segata, N.; Nollo, G.; Tessarolo, F. Dental Implants with Anti-Biofilm Properties: A Pilot Study for Developing a New Sericin-Based Coating. Materials 2019, 12, 2429. [CrossRef]

2. Harris, L.G.; Richards, R.G. Staphylococci and implant surfaces: A review. Injury 2006, 37, 3-14. [CrossRef]

3. Kato, K.; Uchida, E.; Kang, E.T.; Uyama, Y.; Ikada, Y. Polymer surface with graft chain. Prog. Polym. Sci. 2003, 28, 209-259. [CrossRef]

4. Chen, W.; Thomas, J.M. Layer-by-Layer Deposition: A Tool for Polymer Surface Modification. Macromolecules 1997, 30, 78-86. [CrossRef] 
5. Luo, M.L.; Zhao, J.Q.; Tang, W.; Pu, C.S. Hydrophilic modification of poly (ether sulfone) ultrafiltration membrane surface by self-assembly of $\mathrm{TiO}_{2}$ nanoparticles. Appl. Surf. Sci. 2005, 249, 76-84. [CrossRef]

6. Hegemann, D.; Brunner, H.; Oehr, C. Plasma treatment of polymers for surface and adhesion improvement. Nucl. Instrum. Methods Phys. Res. Sect. B 2003, 208, 281-286. [CrossRef]

7. Lee, H.; Dellatore, S.M.; Miller, W.M.; Messersmith, P.B. Mussel-Inspired Surface Chemistry for Multifunctional Coatings. Science 2007, 318, 426-430. [CrossRef]

8. Jiang, J.; Zhu, L.; Zhu, L.; Zhu, B.; Xu, Y. Surface Characteristics of a Self-Polymerized Dopamine Coating Deposited on Hydrophobic Polymer Films. Langmuir 2011, 27, 14180-14187. [CrossRef] [PubMed]

9. Ryu, J.H.; Messersmith, P.B.; Lee, H. Polydopamine Surface Chemistry: A Decade of History. ACS Appl. Mater. Interfaces 2018, 10, 7523-7540. [CrossRef] [PubMed]

10. Salomäki, M.; Martilla, L.; Kivellä, H.; Ouvinen, T.; Lukkari, H. Effects of pH and Oxidants on the First Steps of Polydopamine Formation: A Thermodynamic Approach. J. Phys. Chem. B 2018, 122, 6314-6327. [CrossRef]

11. Liebscher, J.; Mrowczynski, R.; Scheidt, H.A.; Filip, C.; Hadade, D.N.; Turcu, R.; Bende, A.; Beck, S. Structure of Polydopamine: A Never-Ending Story. Langmuir 2013, 29, 10539-10548. [CrossRef] [PubMed]

12. Cîrcu, M.; Filip, C. Closer to the polydopamine structure: New insights from a combined ${ }^{13} \mathrm{C} /{ }^{1} \mathrm{H} /{ }^{2} \mathrm{H}$ solid-state NMR study on deuterated sample. Polym. Chem. 2018, 9, 3379-3387. [CrossRef]

13. Ball, V. Polydopamine Nanomaterials: Recent Advances in Synthesis Methods and Applications. Front. Bioeng. Biotechnol. 2018, 6, 1-12. [CrossRef]

14. Singh, I.; Dhawan, G.; Gupta, S.; Kumar, P. Recent Advances in a Polydopamine Mediated Antimicrobial Adhesion System. Front. Microbiol. 2021, 11, 1-17. [CrossRef] [PubMed]

15. Ball, V. Physicochemical perspective on polydopamine and poly(catechoamine) films for their applications in biomaterial coatings. Biointerphases 2014, 9, 030801. [CrossRef]

16. Shu, H.; Zhou, P.; Wang, L.; Xiong, X.; Zhang, Y.; Deng, Y.; Wei, S. Antibiotic-decorated titanium with enhanced antibacterial activity through adhesive polydopamine for dental/bone implant. J. R. Soc. Interface 2014, 11, 20140169.

17. Lim, K.; Chua, R.R.Y.; Ho, B.; Tambyah, P.A.; Hadinoto, K.; Leong, S.S.J. Development of a catheter functionalized by a polydopamine peptide coating with antimicrobial and antibiofilm properties. Acta Biomater. 2015, 15, 127-138. [CrossRef] [PubMed]

18. Neethu, S.; Midhun, S.J.; Radhakrishnan, E.; Jyothis, M. Surface functionalization of central venous catheterwith mycofabricated silver nanoparticles and its antibiofilm activity on multidrug resistant Acinetobacter baumannii. Microb. Pathog. 2020, $138,103832$. [CrossRef]

19. Petran, A.; Mrowczynski, R.; Filip, C.; Turcu, R.; Liebscher, J. Melanin-like polydopa amides-synthesis and applications in functionalization of magnetic nanoparticles. Polym. Chem. 2015, 6, 2139-2149. [CrossRef]

20. Zhang, C.; Ou, Y.; Lei, W.-X.; Wan, L.-S.; Ji, J.; Xu, Z.-K. CuSO $\mathrm{CH}_{2} \mathrm{H}_{2}$-Induced Rapid Deposition of Polydopamine Coatings with High Uniformity and Enhanced Stability. Angew. Chem. Int. Ed. 2016, 55, 3054-3057. [CrossRef]

21. Tahroudia, Z.M.; Razmjoua, A.; Bagheriana, M.; Asadniac, M. Polydopamine surface modification with UV-shielding effect using $\mathrm{KMnO}_{4}$ as an efficient oxidizing agent. Colloids Surf. A 2018, 559, 68-73. [CrossRef]

22. Khanzada, N.K.; Rehman, S.; Leu, S.Y.; An, A.K. Evaluation of anti-bacterial adhesion performance of polydopamine cross-linked graphene oxide RO membrane via in situ optical coherence tomography. Desalination 2020, 479, 114339. [CrossRef]

23. Luo, C.; Liu, W.; Luo, B.; Tian, J.; Wen, W.; Liu, M.; Zhou, C. Antibacterial activity and cytocompatibility of chitooligosaccharidemodified polyurethane membrane via polydopamine adhesive layer. Carbohydr. Polym. 2017, 156, 235-243. [CrossRef] [PubMed]

24. Ahmed, S.B.; Hasane, A.; Wang, Z.; Mansurov, A.; Castrilloìn, S.R.V. Bacterial adhesion to ultrafiltration membranes: Role of hydrophilicity, natural organic matter, and cell-surface macromolecules. Environ. Sci. Technol. 2018, 52, 162-172.

25. Quinteros, M.A.; Aristizábal, V.C.; Dalmasso, P.R.; Paraje, M.G.; Páez, P.L. Oxidative stress generation of silver nanoparticles in three bacterial genera and its relationship with the antimicrobial activity. Toxicol. In Vitro 2016, 36, 216-223. [CrossRef]

26. Mrówczyński, R.; Coy, L.E.; Scheibe, B.; Czechowski, T.; Augustyniak-Jabłokow, M.; Jurga, S.; Tadyszak, K. Electron Paramagnetic Resonance Imaging and Spectroscopy of Polydopamine Radicals. J. Phys. Chem. B 2015, 119, 10341-10347. [CrossRef] [PubMed]

27. Popa, A.; Raita, O.; Stan, M.; Pana, O.; Borodi, G.; Giurgiu, L.M. Electron Paramagnetic Resonance of Mn-Doped Sn $1-x \mathrm{Mn}_{x} \mathrm{O}_{2}$ Powders. Appl. Magn. Reson. 2012, 42, 453-462. [CrossRef]

28. Miranda, J.E.A.; Sotomayor, C.E.; Albesa, I.; Paraje, M.G. Oxidative and nitrosative stress in Staphylococcus aureus biofilm. FEMS Microbiol. Lett. 2011, 315, 23-29. [CrossRef]

29. Ogunyemi, S.O.; Zhang, M.; Abdallah, Y.; Ahmed, T.; Qiu, W.; Ali, M.A.; Yan, C.; Yang, Y.; Chen, J.; Li, B. The Bio-Synthesis of Three Metal Oxide Nanoparticles $\left(\mathrm{ZnO}, \mathrm{MnO}_{2}\right.$, and $\left.\mathrm{MgO}\right)$ and Their Antibacterial Activity against the Bacterial Leaf Blight Pathogen. Front. Microbiol. 2020, 11, 588326. [CrossRef]

30. Cazzaniga, G.; Ottobelli, M.; Ionescu, A.; Garcia-Godoy, F.; Brambilla, E. Surface properties of resin-based composite materials and biofilm formation: A review of the current literature. Am. J. Dent. 2015, 28, 311-320.

31. Katsikogianni, M.; Missirlis, Y.F. Concise review of mechanisms of bacterial adhesion to biomaterials and of techniques used in estimating bacteria-material interactions. Eur. Cell. Mater. 2004, 8, 37-57. [CrossRef]

32. Liu, Y.; Ai, K.; Lu, L. Polydopamine and Its Derivative Materials: Synthesis and Promising Applications in Energy, Environmental, and Biomedical Fields. Chem. Rev. 2014, 114, 5057-5115. [CrossRef] 
33. Lei, W.; Ren, K.; Chen, T.; Chen, X.; Li, B.; Chang, H.; Ji, J. Polydopamine Nanocoating for Effective Photothermal Killing of Bacteria, and Fungus upon Near-Infrared Irradiation. Adv. Mater. Interfaces 2016, 3, 1600767. [CrossRef]

34. Koopaie, M.; Bordbar-Khiabani, A.; Kolahdooz, S.; Darbandsari, A.K.; Mozafari, M. Advanced surface treatment techniques counteract biofilm-associated infections on dental implants. Mater. Res. Express 2020, 7, 015417. [CrossRef]

35. Feng, Y.; Ma, X.; Chang, L.; Zhu, S.; Guan, S. Characterization and cytocompatibility of polydopamine on MAO-HA coating supported on Mg-Zn-Ca alloy. Surf. Interface Anal. 2017, 49, 1115-1123. [CrossRef]

36. Francolini, I.; Donelli, G.; Crisante, F.; Taresco, V.; Piozzi, A. Antimicrobial Polymers for Anti-Biofilm Medical Devices: State-of-Art and Perspectives. Adv. Exp. Med. Biol. 2015, 831, 93-117.

37. Sadrearhami, Z.; Nguyen, T.-K.; Namivandi-Zangeneh, R.; Jung, K.; Wong, E.H.H.; Boyer, C. Recent Advances in Nitric Oxide Delivery for Antimicrobial Applications Using Polymer-Based Systems. J. Mater. Chem. B 2018, 6, 2945-2959. [CrossRef]

38. Sadrearhami, Z.; Shafiee, F.N.; Ho, K.K.K.; Kumar, N.; Krasowska, M.; Blencowe, A.; Wong, E.H.H.; Boyer, C. Antibiofilm Nitric Oxide-Releasing Polydopamine Coatings. ACS Appl. Mater. Interfaces 2019, 11, 7320-7329. [CrossRef]

39. Pant, J.; Gao, J.; Goudie, M.J.; Hopkins, S.P.; Locklin, J.; Handa, H. A Multi-Defense Strategy: Enhancing Bactericidal Activity of a Medical Grade Polymer with a Nitric Oxide Donor and Surface-Immobilized Quaternary Ammonium Compound. Acta Biomater. 2017, 58, 421-431. [CrossRef] [PubMed]

40. Fleming, G.; Aveyard, J.; Fothergill, J.; McBride, F.; Raval, R.; D'Sa, R. Nitric Oxide Releasing Polymeric Coatings for the Prevention of Biofilm Formation. Polymers 2017, 9, 601. [CrossRef] [PubMed]

41. Peralta, M.A.; da Silva, M.A.; Ortega, M.G.; Cabrera, J.L.; Paraje, M.G. Usnic Acid Activity on Oxidative and Nitrosative Stress of Azole-Resistant Candida albicans Biofilm. Planta Med. 2017, 83, 326-333. [CrossRef] [PubMed]

42. de Mendoza, I.L.I.; Cayero-Garay, A.; Quindós-Andrés, G.; Aguirre-Urizar, J.M. A systematic review on the implication of Candida in peri-implantitis. Int. J. Implant Dent. 2021, 7, 73. [CrossRef] [PubMed]

43. Bürgers, R.; Hahnel, S.; Reichert, T.E.; Rosentritt, M.; Behr, M.; Gerlach, T.; Handel, G.; Gosau, M. Adhesion of Candida albicans to various dental implant surfaces and the influence of salivary pellicle proteins. Acta Biomater. 2010, 6, 2307-2313. [CrossRef] [PubMed] 